\title{
Reading Profiles in Adolescents with Fragile X Syndrome and Down Syndrome
}

\author{
Aníbal Puente ${ }^{*}$, Jesús M. Alvarado 2,3 , Virginia Jiménez ${ }^{2,3}$ and Lourdes Martínez ${ }^{3}$ \\ 1 Universidad Andrés Bello de Chile, Facultad de Educación, Viña del Mar (Chile). \\ 2 Universidad Complutense de Madrid, Instituto de Estudios Biofuncionales (Spain). \\ 3 Universidad Complutense de Madrid, Facultad de Psicología (Spain).
}

\begin{abstract}
Título: Perfiles de lectura en adolescentes con síndrome de X frágil y síndrome de Down.

Resumen: Las personas con síndrome de X frágil (FXS) y con síndrome de Down (DS) leen mejor de lo esperado para su edad mental. Hemos medido tres habilidades básicas de lectura (reconocimiento de palabras, conciencia fonológica y comprensión de lectura), y dos medidas estándar intelectual y verbal: Escalas McCarthy de capacidades de los niños y los Peabody Picture Vocabulary Tests. Las pruebas se aplicaron a 16 adolescentes clasificados como FXS $(M=14.74$ años, $D T=4.03)$ y 16 adolescentes clasificados como DS $(M=15.59$ años, $S D=2.35)$. Para fines de comparación, las pruebas de lectura también se aplicaron a un grupo de desarrollo normal de 70 niños de entre 4.8 y 7 años $(M=6.11, D T=0.71)$. Los niños con DS y FXS mostraron habilidades verbales superiores a su desarrollo cognitivo, especialmente en el grupo FXS. En el rendimiento de lectura, FXS mostraron un nivel de lectura correspondiente a $5 / 6$ de su edad, y para SD 6/7 de la edad de lectura equivalente; sin embargo, ambos grupos mostraron un rendimiento de lectura similar en las tres habilidades de lectura medidas, cuando la edad mental no verbal fue controlada.

Palabras clave: Síndrome de X frágil; síndrome de Down; discapacidad de aprendizaje, comportamiento cognitivo; habilidades de lectura.
\end{abstract}

\section{Introduction}

The genetics of Down Syndrome (DS) and Fragile X Syndrome (FXS) have received greater attention since the early 1990s. DS is caused by having an extra copy of chromosome 21 and is the most common genetic cause of intellectual disability (Abbeduto, Warren, \& Conners, 2007; Barnes, Roberts, Long, Martin, Berni, \& Mandulak, 2009; Roberts, Price, \& Malkin, 2007). Its prevalence is 1 in 700 live births (Centers for Disease Control and Prevention, 2006). According to the Spanish Collaborative Study of Congenital Malformations [Estudio Colaborativo Español de Malformaciones Congénitas], ECEMC), it is estimated that the number of people with DS is 35,000 . From the year 2015, this population has been declining at a constant rate (Huete García, 2016).

FXS is the most common inherited cause of intellectual disability (Barnes et al., 2009; Finestack, Richmond, \& Abbeduto, 2009; Flenthrope \& Brady, 2010) and is caused by a loss of expression of the Fragile $\mathrm{X}$ mental retardation protein (FMRP) (see, Mirrett, Roberts, \& Price, 2003). Its prevalence is 1 in 4,000 males and 1 in 8,000 females (Price, Roberts, Vandergrift, \& Martin, 2007), and those are conservative estimates.

In Spanish studies, the prevalence of FXS has been revised downwards. Of the initial estimates of 1:1,250 affected males in the general population, a prevalence of $1: 4,000$ to 1:6,000 was reported. The figure for the female sex is approximately half $(1: 8,000$ to $1: 12,000)$. The prevalence of car-

* Correspondence address [Dirección para correspondencia]:

Aníbal Puente, Ph.D., Universidad Andrés Bello. Facultad de Educación. Quillota 910. Viña del Mar (Chile). E-mail: anibal.puente@unab.cl
Abstract: Fragile X Syndrome (FXS) and Down Syndrome (DS) read better than expected for their mental age. We have measured three basic reading skills (word recognition, phonological awareness, and reading comprehension), and two standard intellectual and verbal measures: the McCarthy Scales of Children's Abilities and Peabody Picture Vocabulary Tests. The tests were applied to 16 adolescents classified as FXS $(M=14.74$ years old, $S D=4.03)$ and 16 adolescents classified as DS $(M=15.59$ years old, $S D=$ 2.35). For comparison purposes, the reading tests were also applied to a typical develop group of 70 children aged between 4.8 and 7.0 years $(M=$ 6.11, $S D=0.71)$. Children with DS and FXS exhibited verbal skills superior to their cognitive development, especially in the FXS group. In reading performance, FXS showed a reading level corresponding to 5/6 their age, and for SD $6 / 7$ of the equivalent reading age, however, both groups exhibited a similar reading performance in the three reading skills measured, when nonverbal mental age was controlled.

Key words: Fragile X Syndrome, Down Syndrome; Learning Disability, Cognitive Behaviour; Reading Skills.

riers in the population is about 1:250 women, the ratio with respect to male carriers is 3:1 (Ribate Molina, Pié Juste, \& Ramos Fuentes, 2010). Overall, in Spain, there may be 8,000 normal male carriers, 50,000 female carriers and 10,000 affected. It is thought that $80-90 \%$ of cases are not diagnosed (Asociación Síndrome X-Frágil de Madrid, 2016).

The literature contains numerous studies dealing with language development but hardly any research work has been done on analysing reading behaviour, especially in FXS (Adlof, Klusek, Shinkareva, Robinson, \& Roberts, 2015). This gap is particularly severe in Spanish language, which has scarcely any validated instruments for measuring language development in these special groups. This is an especially interesting area of study, as Spanish is a language with transparent orthography, so its development and acquisition can take a different path to that of other languages with opaque orthography, such as English. The review of reading skills learning and acquisition is carried out by analysing the basic components: word recognition, phonological awareness, and reading comprehension (Roberts \& Scott, 2006).

\section{Theoretical Framework}

Reading skills are critical for the success of individuals with intellectual disabilities, as reading achievement is associated with increased vocational opportunities, increased peer acceptance and greater independence in everyday activities. Literacy has received little attention in FXS, the most common inherited cause of intellectual impairment. This study examined the literacy profile of DS and FXS. The aim was to compare and contrast the reading profile of both syndromes and to examine some cognitive features, such as individuals' 
language and memory. In the literature, there are other similar studies of different syndromes, such as Down and Autism, Asperger and FXS, FXS and ADHD (AttentionDeficit-Hyperactivity-Disorder). Parent ratings of children with FXS resulted in higher ADHD-inattentive type and ADHD-hyperactive type T-scores than those of teachers (Sullivan, Hatton, \& Hammer, 2006). While it has long been known that individuals with FXS often exhibit characteristics of autism spectrum disorder (ASD), only recently has the possibility been raised that the two conditions may have considerably more overlap than previously thought. Scientists at various fragile $\mathrm{X}$ laboratories are studying whether this overlap may extend beyond more behavioural similarities and perhaps include genetic or biological components as well. That research may prove to have far-reaching effects (Bailey, Hatton, Skinner, \& Mesivob, 2001).

\section{Down literacy}

In spite of the numerous studies on reading in DS, the mechanisms by which they learn to read, or what level of mastery they can achieve are as unknown yet. Many of them are able to develop some degree of literacy with guidance and exposure (Kay-Raining Bird, Cleave, \& McConnell, 2000), while many others do not master reading. Children with DS can read better than one would expect from their cognitive and/or language level (Byrne, MacDonald, \& Buckley, 2002; Snowling, Hulme, \& Mercer, 2002). Better readers with DS also have better language skills, and their word reading skills are often, though not always, better than their decoding skills (Buckley, 2001; Verucci, Menghini, \& Vicari, 2006).

Recognizing written words is an early reading skill. Several studies (Fowler, Doherty, \& Boyton, 1995; Kay-Raining Bird et al., 2000; Laws \& Gunn, 2002) have reported a significant correlation between word recognition abilities and visual and verbal short-term memory spans in individuals with DS. In a longitudinal study, Kay-Raining Bird et al. (2000) reported that progress in decoding ability was predicted by verbal short-term memory span measured at the start of the study after controlling for chronological age, mental age, and phoneme segmentation ability.

Word recognition can be carried out by two routes: visual and auditory. Strong visual processing skills aid this population in whole-word recognition, but their weak phonological (auditory) memory is thought to hinder phonological decoding. Phonological memory predicts variation in reading ability beyond what could be explained by general cognitive ability (Fowler et al., 1995), suggesting it would be a mistake to focus intervention on whole-word recognition so much that phonological awareness gets overlooked. Similarly, KayRaining Bird et al. (2000) found that phonological memory predicted a 4.5-year delay in word attack ability in a small group of children with DS, controlling for both chronological and mental age.
The second important skill included in our reading model has to do with phonological awareness. Just as phoneme segmentation and rhyme awareness are strongly correlated with the ability to "sound out" words (phonological decoding) in typically developing children (Scarborough, 1998), they are, too, in children with DS (Boudreau, 2002; CardosoMartins \& Frith, 2001; Cupples \& Iacono, 2000; Gombert, 2002; Kay-Raining Bird et al., 2000; Snowling, Hulme, \& Mercer, 2002). Several studies have suggested that phoneme and syllable segmentation, sound deletion, and rhyming are particularly challenging for individuals with DS (Fowler et al., 1995; Cardoso-Martins \& Frith, 2001;Verucci et al., 2006).

Few studies have examined complex literacy skills in individuals with DS, but the available evidence suggests they have difficulties with such advanced skills. Byrne et al. (2002) charted the literacy development of 24 children with DS over a two-year period. Although children with DS made significant improvements in single word reading, no change in reading comprehension was observed. Verucci et al. (2006) found impaired passage comprehension in 17 individuals with DS, as compared to a typically developing control group matched on their accuracy and speed of single word reading. Most children with DS have word-reading and spelling ages ahead of their reading comprehension age (Byrne et al., 2002; Fowler et al., 1995; Groen, Laws, Nation, \& Bishop, 2006). However, that sort of question has not been systematically explored.

One might expect that levels of both vocabulary and grammar comprehension would predict reading comprehension (Nation \& Norbury, 2005; Robert \& Scott, 2006). Another factor we expect to influence reading comprehension in children with DS is their limited working memory capacity. This will affect their ability to decode new text while retaining the meaning of what has already been read (Gathercole \& Pickering, 2001).

Cardoso-Martins, Peterson, Olson, and Pennington (2009) administered a variety of reading tests (including single word recognition, reading comprehension, pseudo-word reading accuracy, and single word spelling) to 20 adolescents with DS and found that their average reading ability was lower than they would have predicted from IQ alone, though skill level varied across participants. Conversely, there is other evidence to suggest that the reading abilities of children with DS are actually higher than their cognitive ability would indicate (Byrne et al. 2002).

There is considerable evidence linking reading development to awareness of the sound structure of spoken language for children with both developmental disabilities and typical development (Cupples \& Iacono, 2000). Numerous studies have demonstrated that phonological awareness can reliably predict individual differences in reading ability (Siegel, 1993; Wagner \& Torgesen, 1987), and that children with greater phonological processing proficiency usually learn to decode words more easily than those with phono- 
logical processing difficulties (Menghini, Verucci, \& Vicari, 2004).

\section{Fragile X literacy}

Few studies have investigated the reading abilities of individuals with FXS, and little is known about the processes that may support literacy in this population. Individuals with FXS exhibit significantly impaired reading skills, including phonological awareness, offset by slightly better whole-word decoding skills. In a national survey of 1,105 families of children with FXS, Bailey, Raspa, Holiday, Bishop and Olmsted (2009) found that only 19\% of adult males with FXS were reported to read books containing new words or concepts. Significant impairments were also detected in basic literacy skills, as only $44 \%$ of adult males with FXS were reported to read basic picture books and 59\% were reported to know letter sounds.

Reading studies have indicated that individuals with FXS tend to read better than expected given their mental age, and that they have more difficulty decoding than sight-word reading. This suggests reading is a strength they could potentially develop. Initially, their strong sight-word recognition skills should be used to teach reading; but later on, extra attention should be paid to developing their knowledge and use of letter-sound rules and decoding skills. Decoding nonwords is especially difficult for individuals with FXS, indicating weak phonological processing of new words.

Phonological skills in FXS may also be weaker than would be expected based on basic reading abilities. JohnsonGlenberg (2008) found that boys with FXS $(n=13)$ who were matched with typically developing children on word identification skills showed phonological decoding skills (measured by performance on a Word Attack Task) that lagged behind those of the controls by about two years.

To explain the shortcomings of reading some cognitive traits should be taken into consideration: children and adolescents preferentially process information in a simultaneous manner and when information is presented sequentially the learning outcome is almost always deficient. For this reason, learning reading, writing and mathematics are often very difficult activities for FXS individuals (Brun i Gasca \& ArtigasPallarés, 2001). However, a prominent cognitive feature is good long-term memory capacity, which may compensate for this deficiency in some way (Fernández, Puente, \& Ferrando-Lucas, 2010; Ferrando-Lucas, Banús-Gómez, \& López-Pérez, 2003).

Clues to what strategies individuals with FXS use in reading acquisition have come from evidence that they perform relatively well on whole word decoding tasks that use real words, but have difficulty on non-word decoding tasks, which require a higher level of phonological processing ability, in a similar way to what happens with DS, as documented in the previous section. Using the Word Identification subtest of the Woodcock Reading Mastery Tests-Revised (Woodcok, 1998), which measures whole word decoding of real words, Johnson-Glenberg (Buckley \& JohnsonGlenberg, 2008; Johnson-Glenberg, 2003) found that an FXS group performed almost as well as a typically developing comparison group matched on mental age. However, they scored significantly lower on the Word Attack subtest, a non-word reading task. Furthermore, when the Word Identification subtest was administered to a younger, typically developing cohort matched on nonverbal mental age, the results were quite different: the FXS group outperformed the younger typical development group. That FXS group's superior performance was likely due to the significant age difference between the two cohorts - the FXS group's average age was approximately 20 years old, whereas the typically developing children were, on average, 5 years and 6 months old. Thus, participants with FXS had a great deal more experience with print and vocabulary. Although these findings of phonological awareness (described previously) are mostly from research in typically developing children, recent studies of children with atypical development have shown a similar pattern (Cardoso-Martins \& Frith, 2001; Gombert, 2002; Laws \& Gunn, 2002; Snowling et al., 2002). In a recent study, Adlof et al (2015) show that, controlling for mental age, both autistic and non-autistic FXS obtain similar results to subjects with typical development. This means that nonverbal mental age could explain the development of phonological awareness for reading. However, it is not known if this variable would explain reading at higher levels, such as reading comprehension.

Higher-level literacy skills like reading comprehension and listening comprehension have not yet been examined. Most of what we currently know about reading in children with DS or FXS is about basic literacy, or in other words, functional reading. A functional reading approach typically uses sight-word instruction to teach children a series of words considered 'functional' for everyday life. Functional reading is important but it is only a small part of reading, so as the major or even sole focus of reading instruction, this approach is severely limited and has limited learning potential.

The purpose of the study is to contribute and expand information on the reading performance of adolescents and adults with DS and FXS. The scientific community and parents' associations frequently ask for greater support in facing the shortage of clinical and empirical information to intervene in the reading and writing skills of these individuals. The reader profile of DS and FXS (especially the latter) is still weak and inconsistent and this explains our interest in reinforcing some of the aspects that have not yet been explored consistently. To do this, we administer the PROBALES test (Puente et al., 2016) which measures three basic reading processes: letter and word recognition, phonological awareness level and the higher level of reading comprehension. The test is applied individually and allows the reading performance profile of each subject to be defined, with their strengths and weaknesses, and the similarities and differences of each group (DS / FXS) to be ascertained. 
Given the shortage of research on reading in children and adolescents with FXS, this study attempts to answer the following questions: 1) What kind of reading strategies do people with FXS use compared to people with DS? 2) What are the strengths and weaknesses of the reading and phonological profiles of adolescents with FXS? 3) Do word recognition skills have less of an impact on reading than phonological skills for people with FXS? 4) What levels of comprehension do FXS reach compared to DS and which cognitive factors are involved in this comprehension process?

\section{Method}

\section{Participants}

The study involved 32 adolescents with DS and FXS, divided into two groups of 16 participants each, all participants were native Spanish speakers. The groups initially had 18 participants with FXS and 16 with DS, but two FXS participants were removed from the sample for not completing the tests. The DS group's average age was 15.59 years old (SD = 2.35) and it had 8 males and 8 females. Meanwhile, the FXS group's average age was 14.74 years old ( $S D=4.03), 12$ of them males and 4 females. To test the reading performance of subjects with typical development, 70 children (34 children and 36 girls) in kindergarten and first grade were selected from 4.8 to 7.0 years of age $(M=6.11, S D=0.71)$.

\section{Instruments}

Peabody Picture Vocabulary Test (PPVT-III; Dunn \& Dunn, 2006). A classic means of assessing performance in common vocabulary is the PPVT-III. It is administered individually with no time limit, and is broad in scope. We used the Spanish adaptation of the third edition (Dunn, Dunn, \& Arribas, 2010). The test is very useful and reliable at evaluating children with typical development, and even some degree of developmental alteration that affects academic performance.

McCarthy Scales of Children's Abilities (MSCA; McCarthy, 1972). The MSCA is individually administered and assesses cognitive development and motor skills in children aged 2.5 to 8.5 years old. We used the Spanish adaptation by Cordero, Seisdedos, González and de la Cruz (2013).

The testing session is about 45 minutes long for children under 5, and an hour for older children. A wide range of puzzles, toys, and game-like activities is used to evaluate each child on five different scales. The Verbal Scale, which has five subtests, assesses comprehension and language use. The Quantitative Scale (three subtests) measures mathematical abilities. The Perceptual-Performance Scale (seven subtests) evaluates a child's ability to conceptualize and reason without words. The Memory Scale (four subtests) tests shortterm recall of words, numbers, pictures, and tonal sequences. Finally, the Motor Scale (five subtests) assesses both gross and fine motor coordination. In addition to individual scores on each scale, the Verbal, Quantitative, and PerceptualPerformance Scales are combined to yield a General Cognitive Index, a measure of overall intellectual functioning expressed as an Equivalent Mental Age between 1.5 and 12.5 years old. In addition to including global cognitive development, the McCarthy Scales are useful for determining areaspecific strengths and weaknesses.

\section{Basic Reading Skill}

For the objective population, there is no specific test or set of tests in Spanish for the evaluation of the three proposed basic reading skills: Recognition, Phonological Awareness and Comprehension (see Roberts \& Scott, 2006) In consequence we developed PROBALES (PROcesos BÁsicos de LEctura, the Spanish acronym for Basic Reading Skills). This instrument has been validated in Spanish samples in school children aged between 4 and 9 years old (Puente et al., 2016) and includes the following scales:

Recognition. Three tasks were designed to assess children's recognition and identification skills, using as points of reference the Word Identification subtests of the Wide Range Achievement Test (Wilkinson, 1993) and the Woodcock Reading Mastery Test (Woodcock, 1987). Tasks:

Symbol Identification. A simple visual stimulus is presented, and respondents must correctly identify it within a set of similar stimuli.

Word Identification. A word written on a card is presented for approximately 20 seconds and then taken away. Respondents must identify the word that matches the card from a set of four options.

Word Recognition. A written list of words is presented visually and respondents must correctly rewrite them. Like the Word Identification task, this requires respondents to activate the word's imprint, hold it in visual memory, and then write it down.

Phonological Awareness. Three tasks were designed to measure phonological processes. These tasks are similar to earlier tests of sound identification and phonological processing (e.g. Lovett et al., 1994; Torgesen \& Wagner, 1999). Tasks:

Letter Sound Identification. The experimenter pronounces aloud the phoneme corresponding to a letter, and respondents must select that letter of the alphabet by circling it.

Rhyme Identification. This involves identifying the word that sounds like the target word.

Listen and Write. Letters and words are presented orally and participants are asked to write them down immediately.

Comprehension. Three tasks were designed to asses reading comprehension. These are common tasks such as the Passage Comprehension subtest of the Woodcock Reading Mastery Test (Woodcock, 1987). Tasks:

Word Completion. A word or phrase is presented from which certain vowels or consonants have been omitted, and respondents must fill in the blanks so it makes sense.

Vocabulary (identify the correct word). This is a test of broad 
vocabulary in which respondents choose the word with the correct spelling from among four very similar options. In this case, the other alternatives are pseudo words, or variants produced by slightly altering the position of a component letter of the word.

Phrase Completion. Respondents select the word that completes the phrase from a list.

\section{Procedure}

All testing materials were placed on students' desks, which were otherwise clear. The children were not permitted to erase anything. The tasks were administered individually. Tree sessions were held and always in the same order: Peabody, McCarthy and PROBALES.

\section{Statistical analysis}

T-test and analysis of variance (ANOVA) were employed to determine the statistical significance of the differences between groups. Linear regression was employed to ascertain which of cognitive subtests best explain reading performance. All analysis were made using SPSS 22 for Windows (SPSS Inc., Chicago, Illinois).

\section{Results}

There is no statistically significant difference, $t(30)=1.18, p$ $=.25$, between FXS and DS groups in the Peabody Vocabulary Test $(M=73.06$ and $S D=1.26$ for FXS, $M=69.86$ and $S D=15.93$ for DS, scores that correspond to a mental age of 6.5 / 6.0 years). Nevertheless. FXS score statistically significantly higher on the Verbal Scale (Verbal Memory I and Pictorial Memory subtests) of the McCarthy (see Table 1). In contrast, the DS group out-performed the FXS group on the McCarthy Perceptual-Performance with statistically significant differences on the following subscales: Block Building, Tapping Sequence, Draw-a-Design, and Draw-a-Child. Differences on other scales fell short of statistical significance $(p$ $<$.05). For instance, the DS group's General Cognitive Indexes (Verbal Scale + Perceptual-Performance + Quantitative) were higher, but not to the level of statistical significance. In conclusion, the results convey better performance in the FXS group on verbal intelligence tests, and in the DS group on nonverbal intelligence tests.

The PROBALES has proved to be a predictive and reliable instrument (Alvarado, Puente, Fernández, \& Jiménez, 2015; Puente et al., 2016) to assess developmental level on reading precursors in Spanish: Cronbach's $\alpha=.91$ for experimental group and Cronbach's $\alpha=.81$ for typical develop group. In Table 2 it can be seen that DS obtain better scores than FXS in all reading tasks, with the differences in the scales of Recognition (Symbol Identification and Word Identification Subscales) and Comprehension (only at the overall score level) being statistically significant.
Table 1. McCarthy mean scores for DS and FXS (SD in brackets).

\begin{tabular}{lcc}
\hline Scales/Subscales & DS & FXS \\
\hline Opposite Analogies & $8.00(3.72)$ & $10.12(3.35)$ \\
Pictorial Memory & $3.69(1.35)$ & $4.71(1.40)^{*}$ \\
Verbal Fluency & $17.75(6.88)$ & $20.59(4.68)$ \\
Verbal Memory I & $7.06(3.96)$ & $9.82(3.17)^{*}$ \\
Verbal Memory II & $3.38(2.39)$ & $5.00(2.29)$ \\
Word Knowledge & $16.50(5.51)$ & $18.82(3.81)$ \\
Verbal Scale & $\mathbf{5 6 . 3 8 ( 1 9 . 8 2 )}$ & $\mathbf{6 9 . 0 6}(\mathbf{1 4 . 9 6})^{*}$ \\
Mental Age & $\mathbf{5 . 0}[\mathbf{3 . 5 ; 6 . 5}]$ & $\mathbf{6 . 5}[\mathbf{5 . 0 ;} \mathbf{7 . 5}]$ \\
Conceptual Grouping & $7.79(2.89)$ & $6.13(2.29)$ \\
Block Building & $10.50(1.79)^{* *}$ & $8.27(1.75)$ \\
Draw-a-Child & $11.50(2.88)^{*}$ & $8.67(3.66)$ \\
Draw-a-Design & $11.56(5.14)^{*}$ & $7.53(3.28)$ \\
Puzzle Solving & $8.93(3.10)$ & $6.93(3.39)$ \\
Right-Left Orientation & $6.57(2.24)$ & $5.00(3.40)$ \\
Tapping Sequence & $4.21(1.48)^{* *}$ & $2.07(1.03)$ \\
Perceptual-performance & $\mathbf{6 0 . 9 3 ( 1 3 . 3 3 ) * *}$ & $\mathbf{4 4 . 1 3 ( 1 4 . 1 8 )}$ \\
Mental Age & $\mathbf{5 . 5}[\mathbf{4 . 5 ; 6 . 5 ]}$ & $\mathbf{4 . 5}[\mathbf{3 . 5 ; 5 . 0 ]}$ \\
Counting and Sorting & $6.29(2.49)$ & $4.67(2.77)$ \\
Number Questions & $9.86(3.63)$ & $7.60(2.64)$ \\
Numerical Memory I & $3.44(1.31)$ & $3.53(1.81)$ \\
Numerical Memory II & $2.25(2.05)$ & $1.18(1.74)$ \\
Quantitative & $\mathbf{2 1 . 9 3 ( 7 . 9 2 )}$ & $\mathbf{1 6 . 6 0 ( 6 . 5 2 )}$ \\
Mental Age & $\mathbf{5 . 0}[\mathbf{3 . 5 ; 5 . 5 ]}$ & $\mathbf{4 . 0}[\mathbf{3 . 0 ; 5 . 0 ]}$ \\
\hline
\end{tabular}

$* p<.05 ;{ }^{* *} p<.01$

Table 2. Reading Skill measured by PROBALES.

\begin{tabular}{lcc}
\hline MEASURES & SD & FXS \\
\hline Symbol Identification & $6.06(1.00)^{* *}$ & $4.56(1.55)$ \\
Word Identification & $4.69(2.12)^{*}$ & $2.75(2.65)$ \\
Word Recognition & $7.38(3.32)$ & $4.94(4.20)$ \\
Recognition Scale & $\mathbf{1 8 . 1 3 ( 5 . 5 5 ) *}$ & $\mathbf{1 2 . 2 5 ( 7 . 3 9 )}$ \\
Rhyme Identification & $3.25(1.48)$ & $2.63(1.67)$ \\
Letter Sound Identification & $4.75(4.37)$ & $3.13(4.03)$ \\
Listen and Write & $7.75(4.27)$ & $5.50(4.13)$ \\
Phonological Scale & $\mathbf{1 5 . 7 5 ( 8 . 3 9 )}$ & $\mathbf{1 1 . 2 5 ( 8 . 3 0 )}$ \\
Vocabulary & $4.06(2.21)$ & $2.94(2.35)$ \\
Word Completion & $4.50(3.35)$ & $2.31(2.77)$ \\
Phrase Completion & $2.69(3.05)$ & $0.94(2.05)$ \\
Comprehension Scale & $\mathbf{1 1 . 2 5 ( 7 . 3 6 ) *}$ & $\mathbf{6 . 1 9 ( 6 . 0 3 )}$ \\
TOTAL SCORES & $\mathbf{4 5 . 1 3 ( 2 0 . 0 6 ) *}$ & $\mathbf{2 9 . 6 9 ( 2 0 . 2 4 )}$ \\
\hline$* p<.05 ; * *<.01$ & &
\end{tabular}

To measure the reading level of children with typical development and comparable mental age, the test was administered to a sample of 70 children aged between 4.8 and 7 years, estimating the equation of linear regression between age and the three PROBALES scales, and generally obtaining a good fit: Scale of Recognition $R=.40\left(R_{\text {adj }}^{2}=.15\right)$; Scale of Phonological Awareness $R=.72\left(R_{\text {adj }}^{2}=.51\right)$; Scale of Comprehension $R=.73\left(R^{2}\right.$ adj $\left.=.52\right)$ and Global Reading $R=.77\left(R_{\text {adj }}^{2}=.58\right)$. These equations were used to convert reading scores into equivalent reading ages in subjects with typical development and the differences in reading between DS and FXS were analysed by means of a repeated measures Analysis of Variance (ANOVA).

The ANOVA (groups = comparison DS and FXS, repeated measure $=$ reading measure to Recognition, Phonological and Comprehension) shows a main effect of repeated 
reading measure $\mathrm{F}(2,60)=148.35, p<.001, \eta_{\mathrm{p}}{ }^{2}=.83$, and the group (DS vs FX) $\mathrm{F}(1,30)=4.79, p=.037, \eta_{\mathrm{p}}^{2}=.14$. There was no significant interaction effect between reading measures (Recognition, Phonological and Comprehension) and group $\mathrm{F}(2,30)=0.71, p=.50, \eta_{\mathrm{p}}{ }^{2}=.02$. However, if non-verbal mental age is controlled and the two non-verbal McCarthy measurements are introduced as co-variables in the ANOVA ( 3 FXS and 2 DS were excluded because of missing data for these covariates), the ANOVA showed a main effect of reading measurement $\mathrm{F}(2,46)=7.02, p=.002$, $\eta_{\mathrm{p}}{ }^{2}=.23$, but the group $\mathrm{F}(1,23)=0.31, p=.59, \eta_{\mathrm{p}}{ }^{2}=.01$ was no longer significant, nor was there interaction between reading measurement and group $\mathrm{F}(2,30)=0.19, p=.83, \eta_{\mathrm{p}}{ }^{2}$ $=.01$. Both co-variables were significant: Perceptive $\mathrm{F}(1,23)=6.82, p=.016, \eta_{\mathrm{p}}^{2}=.23$ and Quantitative $\mathrm{F}(1,23)=$ $10.22, p=.004, \eta_{\mathrm{p}}^{2}=.31$ (See Figure 1).
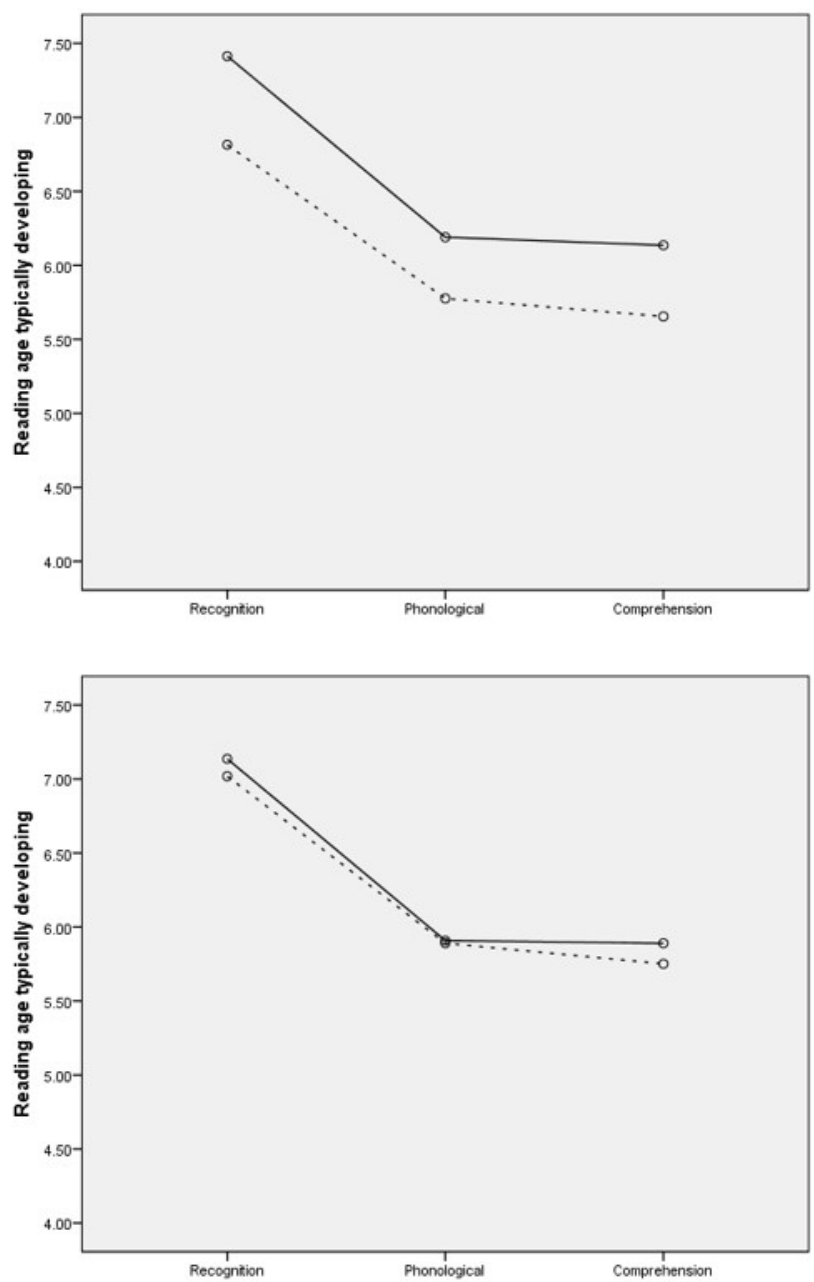

Figure 1. Average scores on the reading scales (transformed to typical development reading age) for the DS (continuous line) and FXS (dashed line) groups. The figure on the left shows the results without co-variates, whilst in the figure on the right the McCarthy measurements for non-verbal aspects were introduced as co-variables.
Regarding the overall performance in reading, the regression model based on the non-verbal scales showed a validity coefficient $R=.84\left(R_{\text {adj }}^{2}=.72\right)$ for the PerceptiveManipulative Scale, $\beta=.46, p=.005$, and for the Quantitative scale $\beta=.48, p=.004$. (See Figure 2)

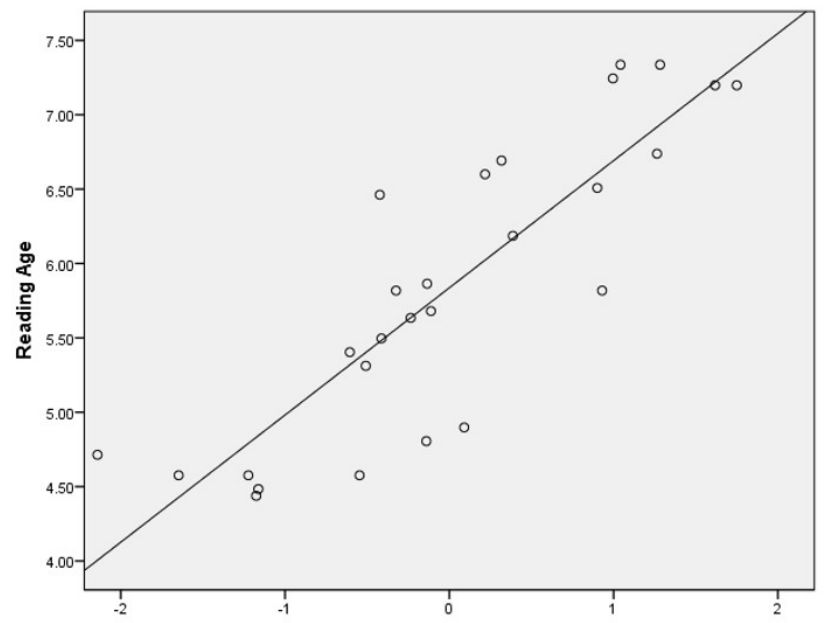

Figure 2. Plots of Reading Age values against standardized predicted nonverbal mental age

As a result, if non-verbal mental age is controlled, the differences between the groups disappeared in the three reading measurements. These results enabled both groups to be analysed together to ascertain which aspects of intelligence allow reading performance to be predicted. We performed regression analysis (see Table 3) to determine which McCarthy variables correctly predicted reading ability, as measured by the PROBALES and its Subscales.

Table 3. Standardized Coefficients $(\beta), t$ values, and significance level for each McCarthy predictor variable on the PROBALES Subscales.

\begin{tabular}{|c|c|c|c|}
\hline MEASURES & $\beta$ & $t$ & $p$ \\
\hline \multicolumn{4}{|l|}{ Recognition $\left(R^{2}{ }_{\text {adj }}=.72\right)$} \\
\hline Block Building & .434 & 3.474 & .002 \\
\hline Number Questions & .405 & 3.615 & .002 \\
\hline Right-Left Orientation & .317 & 2.627 & .015 \\
\hline \multicolumn{4}{|l|}{ Phonology $\left(R^{2}\right.$ adj $\left.=.68\right)$} \\
\hline Tapping Sequence & .720 & 6.295 & .000 \\
\hline Word Knowledge (Vocabulary) & .489 & 4.278 & .000 \\
\hline \multicolumn{4}{|l|}{ Comprehension $\left(R^{2}{ }_{\text {adj }}=.82\right)$} \\
\hline Tapping Sequence & .523 & 4.828 & .000 \\
\hline Opposite Analogies & .293 & 3.243 & .004 \\
\hline Draw-a-Design & .334 & 3.082 & .006 \\
\hline Right-Left Orientation & .217 & 2.372 & .027 \\
\hline \multicolumn{4}{|l|}{ PROBALES $\left(R^{2}{ }_{\text {adj }}=.76\right)$} \\
\hline Tapping Sequence & .780 & 8.006 & .000 \\
\hline Word Knowledge (Vocabulary) & .485 & 4.981 & .000 \\
\hline
\end{tabular}

Table 3 illustrates that the Recognition Scale was strongly related to competencies such as Block Building, Number Questions, and Right-Left Orientation (explaining $72 \%$ of variance). As for the Phonology scale, $68 \%$ of its variance 
could be explained by Tapping Sequence and Word Knowledge scores. $76 \%$ of variance in Comprehension was explained by the variables Tapping Sequence, Opposite Analogies, Draw-a-Design, and Right-Left Orientation. In any case, the Phonology skills - Tapping Sequence and Word Knowledge - were the best predictors of overall reading performance as measured by the PROBALES; together they explained $76 \%$ of variance.

\section{Discussion}

Learning to read and developing literacy skills can be useful in everyday life for individuals with DS and FXS. Research on reading development in children with DS has indicated they can often read better than might be expected (Finestack \& Abbeduto, 2010). This research compares reading profiles in Spanish in DS and FXS adolescents and attempting to identify underlying cognitive mechanisms. The assessment procedure was to administer the PROBALES test, which is structured around three basic reading skills: word recognition, phonological awareness, and sentence reading comprehension (Roberts \& Scott, 2006). To obtain the reading profile and the underlying cognitive mechanisms is a complex task. For this reason, our results should be considered with some caution as they may result in controversial appearance.

The two experimental groups, FXS and DS, are homogeneous in total IQ, but their cognitive profile is different. FXS are superior in verbal IQ, this superiority is due to better performance in tasks of immediate memory with visual or verbal elements (Pictorial Memory and Verbal Memory I Subtests). DS are superior in the manipulative perceptual scale. This superiority is due to good results obtained in Block Building, Draw- a-Design, Draw-a-Child and Tapping Sequence, i.e. constructive, coordination and visuospatial integration praxias that relate to phonological decoding and correlate with phonological awareness (Boudreau, 2002; Cardoso-Martins \& Frith, 2001; Scarborough, 1998; Snowling, Hulme, \& Mercer, 2002). Individuals with DS face particular challenges in phoneme and syllable segmentation, sound deletion, and rhyming (Verucci et al., 2006). Buckley (2001) argues that when children with SD receive reading training from an early age of 3 years, they reach far higher levels of reading development than when they start reading at 6 years of age. They show significant advances in speech, language, reading and short-term memory skills during their childhood and adolescence. According to Buckley there are at least two reasons to explain the improvement: firstly, as explained, visuospatial processing is better preserved than auditory in people with SD. Secondly, duplication of the message (verbal and written) favors the storage in memory of the structures involved in the language.

The reading level of adolescents FXS and DS was between 5 and 6 years of age in children with typical development. This result is according to the considerable evidence to suggest syntax delays in DS and male FXS. Both receptive and expressive syntax abilities are lower than expected from their nonverbal cognitive ability (Caselli, Monaco, Trasciani, \& Vicari, 2008, Roberts, Price, \& Malkin, 2007). Indeed, young individuals with DS exhibit even more syntactic delay than those with female FXS (Finestack \& Abbeduto, 2010; Price \& Kent, 2008).

Regression analysis using McCarthy scores to predict PROBALES scores reveals that Tapping Sequence showed the highest explained variance and accounted for the greatest difference in reading behavior between the two experimental groups. Tapping Sequence is an activity in which a xylophone repeats a sequence of notes played by an examiner. The task assesses immediate memory for non-verbal material, and measures a child's attentional ability and perceptualmotor coordination (Cornish, Turk, \& Hagerman, 2008). FXS group scored very low when prompted to immediately recall the sequence of sounds. This pattern of auditory memory deficit could partially explain those participants' phonological memory performance. Another factor in the FXS group's poor performance was the visual processing of words, which is distinctly predominant in these individuals. It is sometimes their only means of accessing word reading. Clinical reports by Braden (2002) and Spiridigliozzi et al. (1994) have also supported weaknesses in word decoding skills and relative strengths in familiar word decoding in FXS. Given these reports, it has been suggested that children with FXS rely on different sub-processes to identify words than typically developing children, with greater dependence on a gestalt or "whole-word" approach to word decoding. This form of processing facilitates overall word recognition, but words cannot all be read this way, so a second means of phonological sequence processing is needed. When visual processing is dominant and/or used exclusively, it interferes with developing the phonological component of memory and hinders phonological decoding (Fowler et al., 1995). Excluding phonological awareness from the first phase of reading acquisition is a common cause of poor reading performance in children with both typical and atypical development (Snowling, 1980). Yet, emerging evidence suggests that, despite relative weaknesses in this domain, phonological ability may be an important predictor of reading achievement in FXS. In one study of 54 boys with FXS, phonological awareness accounted for significant variability in both concurrent and later letter/word identification skills (Adlof et al., 2015). Individuals with FXS also show significant weakness in pragmatic skills, and their ability to identify and provide necessary informative details in conversation is impaired more than one would expect from their levels of cognitive development. Their use of repetitive language is also significantly greater than their mental age would indicate; some have suggested that characteristic is unique to FXS. Some pragmatic aspects of language were at work in the more complex comprehension tasks, like completing and interpreting short sentences on the Listen and Write task. Pragmatic competencies are needed to support social language use, such as using language for different purposes (e.g., greeting, informing, requesting, commenting), changing lan- 
guage based on the needs of the listener (e.g., speaking differently to a baby than an adult), and following conversational and storytelling rules (e.g., rephrasing when misunderstood, introducing characters in a story). Several studies have showed the pragmatic language skills of individuals with FXS to present particular challenges (Ferrier, Bashir, Meryash, \& Johnston, 1991; Roberts et al., 2007).

We obtained significant results favoring the DS group on recognition tasks and comprehension tasks. According to the results, there appears to be a predictive relationship between the perceptual-performance scale and outcomes on the reading tasks. In fact, when non-verbal mental age is controlled (perceptual-performance \& quantitative) the differences in reading between the two groups disappears, confirming that "non-verbal mental age" is a key variable for explaining the difference in reading between FX and DS groups. This result is consistent with that reported by Adlof et al. (2015), by controlling this variable the differences in reading between autistic and non-autistic FX disappear. In our study, we extend this conclusion to DS and to other linguistic skills such as comprehension in a transparent language like Spanish, so this result becomes even more generalized.

For both, children and adolescents with DS or FXS, who aspire to a higher level of reading mastery and want to expand their reading skills, must be trained to use the most demanding strategies for comprehension. If discriminating sounds is still difficult for a reader, the next goal might be to work on the meaning of morphemes. For example, separating a word into syllables and recognizing the meaning of prefixes and/or suffixes could be an effective way to expand

\section{References}

Abbeduto, L., Brady, N., \& Kover, S. T. (2007). Language development and fragile X syndrome: Profiles, syndrome-specificity, and withinsyndrome differences. Mental Retardation and Developmental Disabilities Research Reviews, 13(1), 36-46.

Abbeduto, L., Warren, S. F., \& Conners, F. A. (2007). Language development in Down syndrome: From the prelinguistic period to the acquisition of literacy. Mental Retardation and Developmental Disabilities Research Reviews, 13, 247-261.

Adlof, S. M., Klusek, J., Shinkareva, S. V., Robinson, M. L., \& Roberts, J. E. (2015). Phonological awareness and reading in boys with fragile $\mathrm{X}$ syndrome. Journal of Child Psychology and Psychiatry,56(1), 30-39. doi: $10.1111 /$ jcpp. 12267

Alvarado, J. M., Puente, A., Fernández, M. P., \& Jiménez, V. (2015). Análisis de los componentes en la adquisición de la lectura en castellano: una aplicación del modelo logístico lineal [Component analysis of Spanish reading process: an application of the linear logistic test model]. Suma Psicológica, 22(1), 45-52. doi: 10.1016/j.sumpsi.2015.05.006

Asociación Síndrome X-Frágil de Madrid. (2016). Retrieved from http://www.xfragil.net/xfragil/4-que-es

Bailey, D. B., Hatton, D. D., Skinner, M., \& Mesivob, G. (2001). Autism behavior, FMR1 protein, and developmental trajectories in young males with Fragile X symptoms and Down syndrome. Journal of Autism and Developmental Disorders, 31, 165-174.

Bailey, D. B., Raspa, M., Holiday, D., Bishop, E., \& Olmsted, M. (2009). Functional skills of individuals with fragile $\mathrm{x}$ syndrome: a lifespan cross-sectional analysis. American Journal on Intellectual and Developmental Disabilities, 114(4), 289-303.doi: 10.1352/1944-7558-114.4.289-303

Barnes, E., Roberts, J. E., Long, S. H., Martin, G. E., Berni, M. C., \& Mandulak, K. C. (2009). Phonological accuracy and intelligibility in connect- vocabulary. Johnson and Myklebust (1967) propose that placing lines between syllables is not useful since it can distort the image of the word and cause confusion. A better technique would be to put spaces between the parts of a word to help focus the child's vision and facilitate their scrutiny of word parts (Fernández, Puente, \& Ferrando-Lucas, 2011).

Both this study and those in which reading difficulties experienced by DS and FXS have been assessed have the limitation of a lack of control over the comorbidities of this group of subjects, as it is practically impossible to make up pure groups of DS and FXS, thus for example FXS is usually linked with autism, attention deficit and hyperactivity, and is not expressed in the same way in men as in women. In this sense, finding a common denominator of "non-verbal mental age" is a significant advance for unifying the huge variability that characterizes these groups. In any case, it would be necessary to obtain larger samples and replicate the results in other samples. Although there are scarcely any instruments in Spanish to evaluate reader performance, it would be desirable to develop new instruments to compare the results obtained with the PROBALES. Similarly, it would also be desirable to extend cognitive diagnostic batteries for a greater generalization of the results obtained in the present study.

Acknowledgements.- We thank the schools, participants and families who participated in this research. The authors have declared that they do not have any potential or competing conflicts of interest and we confirm that all the research meets the ethical guidelines, including adherence to the legal requirements of the study country.

ed speech of boys with fragile X syndrome or Down syndrome. Journal of Speech, Language, and Hearing Research, 52(4), 1048-1061. doi:10.1044/1092-4388(2009/08-0001)

Boudreau, D. (2002). Literacy skills in children and adolescents with Down syndrome. Reading and Writing: An Interdisciplinary Journal, 15, 497-525.

Braden, M. L (2002). Academic interventions. In: Hagerman, R. J., Hagerman, P. J, editors. In Fragile X syndrome: Diagnosis, treatment, and research. JHU Press; Baltimore, MD (pp. 428-464).

Brun i Gasca, C., \& Artigas-Pallarés, J. (2001). Aspectos psicolingüísticos en el síndrome X frágil. Revista de Neurología, 33 (Supl.1), 29-32.

Buckley, S. J., \& Johnson-Glenberg, M. (2008). Increasing literacy learning for individuals with Down syndrome and fragile X syndrome. In J. E. Roberts, R. S. Chapman\& S. F. Warren (Eds.), Speech \& language development \& intervention in Down syndrome \& fragile $x$ syndrome (pp. 233-254). Baltimore: Paul H. Brookes Publishing Co., Inc.

Buckley, S. (2001). Reading and writing for individuals with Down syndrome: An overview. Portsmouth, Inglaterra: Down Syndrome Educational Trust.

Byrne, A., MacDonald, J., \& Buckley, S. F. (2002). Reading, language and memory skills: A comparative longitudinal study of children with Down syndrome and their mainstream peers. British Journal of Educational Psychology, 72(4), 513-529. doi:10.1348/00070990260377497

Cardoso-Martins, C., Peterson, R., Olson, R., \& Pennington, B. (2009). Component reading skills in Down syndrome. Reading and Writing, 22, 277-92. doi:10.1007/s11145-007-9114-6

Cardoso-Martins, C., \& Frith, U. (2001). Can individuals with Down syndrome acquire alphabetic literacy skills in the absence of phoneme awareness? Reading and Writing, 14(3), 361-375. 
Caselli, M. C., Monaco, L., Trasciani, M., \& Vicari, S. (2008). Language in Italian children with Down syndrome and with specific language impairment. Neuropsychology,22, 27-35. doi: 10.1037/0894-4105.22.1.27

Centers for Disease Control and Prevention. Improved national prevalence estimates for 18 selected major birth defects - United States, 1999 2001. Morbidity and Mortality Weekly Report. 2006; 54, 1301-1305.

Cordero, A., Seisdedos, N., González, M., \& de la Cruz, M. V. (2013). MSCA: Escalas McCarthy de aptitudes y psicomotricidad para niños: Manual. Madrid, España: TEA Ediciones.

Cornish, K. M., Turk, J., \& Hagerman, R. (2008). The fragile X continuum: New advances and perspectives. Journal of Intellectual Disability Research, 52(6), 469-482. doi:10.1111/j.1365-2788.2008.01056.x

Cupples, L., \& Iacono, T. (2000). Phonological awareness and oral reading skill in children with Down syndrome. Journal of Speech, Language, and Hearing Research, 43, 595-608. doi:10.1044/jslhr.4303.595

Dunn, L. M., Dunn, L. M., \& Arribas, D. (2010). PPVT-III, Peabody Picture Vocabulary Test. Madrid, España: TEA Ediciones.

Fernández, M. P., Puente, A., \& Ferrando-Lucas, M. T. (2011). Lectura y escritura en niños con syndrome $\mathrm{x}$ frágil: Estrategias de intervención [Reading and writing in children with fragile $\mathrm{x}$ syndrome: Intervention strategies]. Anales de Psicología, 27(3), 807-815.

Fernández, M. P., Puente, A., \& Ferrando-Lucas. M. T. (2010). Síndrome X frágil: Desarrollo e intervención del lenguaje escrito. Revista chilena de neuropsiquiatría, 48 (3), 219-231.

Ferrando-Lucas, M. T., Banús-Gómez, P. \&, López-Pérez, G. (2003). Aspectos cognitivos y del lenguaje en niños con síndrome X-frágil. Revista de Neurología, 36 (Supl.1), 137-142.

Ferrier, L J., Bashir, A. S., Meryash, D. L., \& Johnston J. (1991). Conversational skills of individuals with fragile-X syndrome: A comparison with autism and Down syndrome. Developmental Medicine \& Child Neurology, 33(9):776-788. doi: 10.1111/j.1469-8749.1991.tb14961.x

Finestack, L. H., Richmond, E., \& Abbeduto, L. (2009). Language development in individuals with fragile $\mathrm{x}$ syndrome. Topics in Language Disorders, 29(2), 133-48. doi:10.1097/TLD.0b013e3181a72016

Finestack, L. H., \& Abbeduto, L. (2010). Expressive language profiles of verbally expressive adolescents and young adults with Down syndrome or fragile X syndrome. Journal of Speech, Language, and Hearing Research, 53, 1334-1348. doi:10.1044/1092-4388(2010/09-0125)

Flenthrope, J., \& Brady, N. (2010). Relationships between early gestures and later language in children with fragile $\mathrm{X}$ syndrome. American Journal of Speech-Language Pathology, 19, 135-142. doi:10.1044/1058-0360(2009/090018)

Fowler, A. E., Doherty, B. J., \& Boyton, L. (1995). The basis of reading skills in young adults with Down syndrome. In L. Nadel \& D. Rosenthal (Eds.), Down syndrome: Living and learning in the community (pp. 182196). New York, EEUU: Wiley Liss.

Gathercole, S. E., \& Pickering, S. J. (2001). Working memory deficits in children with special educational needs. British Journal of Educational Psychology, 28(2), 89-97.

Gombert, J. E. (2002). Children with Down syndrome use phonological knowledge in reading. Reading and Writing, 15(5), 455-469.

Groen, M., Laws, G., Nation, K., \& Bishop, D. V. M. (2006). A case of exceptional reading accuracy in a child with Down syndrome: Underlying skills and the relation to reading comprehension. Cognitive Neuropsycho$\log y, 23(8), 1190-1214$. doi:10.1080/02643290600787721

Huete García, A. (2016). Demografía e inclusión social de las personas con síndrome de Down. Revista Sindrome de Down, 33, 38-50.

Johnson-Glenberg, M. C. (2003). Literacy and working memory in those with fragile $X$ syndrome. Paper presented at the 24th annual meeting of the Society for Research on Children's Language Disorders, Madison, WI.

Johnson-Glenberg, M. C. (2008). Fragile X syndrome: Neural network models of sequencing and memory. Cognitive Systems Research, 9(4), 274292. doi:10.1016/j.cogsys.2008.02.002

Johnson, D. J., \& Myklebust, H. R. (1967). Learning disabilities: Education principles and practices. New York, EEUU: Grune \& Stratton, Inc.

Kay-Raining Bird, E., Cleave, P. L., \& McConnell, L. M. (2000). Reading and phonological awareness in children with Down syndrome: A longitudinal study. American Journal Speech Language Pathology, 9, 319-330.
Laws G., \& Gunn D. (2002). Relationships between reading, phonological skills and language development in individuals with Down syndrome: A five year follow-up study. Reading and Writing, 15(5), 527-548.

Lovett, M. W., Borden, S. L., DeLuca, T., Lacerenza, L., Benson, N. J., \& Brackstone, D. (1994). Treating the core deficits of developmental dyslexia: Evidence of transfer of learning after phonologically- and strategy-based reading programs. Developmental Psychology, 30, 805-822. doi:10.1037/0012-1649.30.6.805

McCarthy, D. (1972). A manual for the McCarthy Scales of Children's Abilities. New York, EEUU: Psychological Corporation.

Menghini, D., Verucci, L., \& Vicari, S. (2004). Reading and phonological awareness in Williams syndrome. Neuropsychology, 18, 29-37. doi:10.1037/0894-4105.18.1.29

Mirrett, P., Roberts, J., \& Price, J. (2003). Early intervention practices and communication intervention strategies for young males with fragile $\mathrm{X}$ syndrome. Language, Speech, and Hearing Services in Schools, 34, 320-331. doi:10.1044/0161-1461(2003/026)

Nation, K., \& Norbury, C. F. (2005). Why reading comprehension fails: Insights from developmental disorders. Topics in Language Disorders, 25(1), 21-32. doi:10.1097/00011363-200501000-00004

Puente, A., Alvarado, J. M., Fernández, P., Rosselli, M., Ardila, A., \& Jiménez, A. (2016). Assessment of Reading Precursors in Spanish-Speaking Children. The Spanish Journal of Psychology, 19(e85), 1-12. doi:10.1017/sjp.2016.92

Price, J., Roberts, J., Vandergrift, N., \& Martin, G. (2007). Language comprehension in boys with fragile $\mathrm{X}$ syndrome and boys with Down syndrome. Journal of Intellectual Disability Research, 51, 318-326. doi:10.1111/j.1365-2788.2006.00881.x

Price, J. R., \& Kent, R. D. (2008). Increasing speech intelligibility in Down syndrome and fragile X syndrome. In J. E. Roberts, R. S. Chapman\& S. Warren (Eds.) Speech and language development and intervention in Down syndrome and fragile X syndrome (pp. 219-232). Baltimore, EEUU: Brookes.

Ribate Molina, M. P., Pié Juste, J., \& Ramos Fuentes, F. J. (2010). Síndrome X Frágil. Protocolos Diagnósticos y Terapéuticos en Pediatría. 1, 85-90.

Roberts, J. A., \& Scott, K. A. (2006). The simple view of reading: Assessment and intervention. Topics in Language Disorders, 26(2), 127-143. doi:10.1097/00011363-200604000-00005.

Roberts, J., Martin, G., E., Moskowitz, L., Harris, A. A., Foreman, J., \& Nelson, L. (2007). Discourse skills of boys with fragile X syndrome in comparison to boys with Down syndrome. Journal of Speech, Language, and Hearing Research.50 (2):475-492 doi:10.1044/1092-4388(2007/033)

Roberts, J. E., Price, J., \& Malkin, C. (2007). Language and communication development in Down syndrome. Mental Retardation and Developmental Disabilities Research Reviews, 12, 26-35. doi:10.1002/mrdd.20136

Scarborough, H. S. (1998). Early identification of children at risk for reading disabilities: Phonological awareness and some other promising predictors. In B. K. Shapiro, P. J. Accardo \& A. J. Capute (Eds.) Specific reading disability: $A$ view of the spectrum (pp. 75-119). Timonium, EEUU: York Press.

Siegel, L. S. (1993). Phonological processing deficits as the basis of a reading disability. Developmental Review, 13(3), 246-257. doi:10.1006/drev.1993.1011

Snowling, M. J. (1980). The development of grapheme-phoneme correspondence in normal and dyslexic readers. Journal of Experimental Child Psychology, 29, 294-305.

Snowling, M. J., Hulme, C., \& Mercer, R. C. (2002). A deficit in rime awareness in children with Down syndrome. Reading and Writing, 15(5), 471495.

Spiridigliozzi, G., Lachiewicz, A., MacMordo, C., Vizoso, A., O'Donnell, C., McConkie-Rosell, A., \& Burgess D. (1994). Educating boys with fragile $x$ syndrome: A guide for parents and professionals. Duke University Medical Center; Durham, NC, EEUU.

Sullivan, K., Hatton D., \& Hammer, J. (2006). ADHD symptoms in children with FXS. American Journal of Medical Genetics. Part A; 140A, 22752288.

Torgesen, J. K., \& Wagner, R. K. (1999). The comprehensive test of phonological processing (CTOPP). Austin, EEUU: TX: PRO-ED.

Verucci, L., Menghini, D., \& Vicari, S. (2006). Reading skills and phonological awareness acquisition in Down syndrome. Journal of Intellectual Disability Research, 50, 477-491. doi:10.1111/j.1365-2788.2006.00793.x 
Wagner, R. K., \& Torgesen, J. K. (1987). The nature of phonological processing and its causal role in the acquisition of reading skills. Psychological Bulletin, 101(2), 192-212. doi:10.1037/0033-2909.101.2.192

Wilkinson, G. S. (1993). The Wide Range Achievement Test-3 (WRAT-3). Wilmington, EEUU, DE: Wide Range.

Woodcock, R. W. (1987). Woodcock Reading Mastery Tests-Revised (WRMT-R). Circle Pines, MN, EEUU: American Guidance Service.
Woodcock, R. W. (1998). Woodcock Reading Mastery Test-Revised-Normative Update (WMRT-R/NU). Circle Pines. MN, EEUU: American Guidance Service.

(Article received: 11-10-2016; revised: 16-12-2016; accepted: 24-02-2017) 